\title{
EVALUATING ETHICS IN DISTANCE EDUCATION LEARNING FROM A STUDENTS POINT OF VIEW
}

\author{
Adnan Chawdhry, California University of PA, chawdhry_a@calu.edu \\ Karen Paullet, Robert Morris University, paullet@rmu.edu \\ David M. Douglas, Robert Morris University,douglas@rmu.edu
}

\begin{abstract}
Popularity in distance education continues to grow each year as developments in worldwide mobility continues to grow. Students are faced with ethical considerations when taking online classes. In academia, ethics is a common phrase placed around academic dishonesty. This exploratory study of 457 undergraduate and graduate students will assess student's ethical perspectives about their own behavior and what external resources they deem as acceptable use in online courses. Additionally, it is important to understand how students' perspectives correlate with demographic characteristics and level of education for faculty and administrators to effectively develop online courses for their students.
\end{abstract}

Keywords: Online learning, ethics, academic integrity, cheating

\section{INTRODUCTION}

The study of ethics, at least in the understanding of declared "Western tradition" is often attributed to the fifth century B.C.E. Greek philosopher Socrates. Here in lies a major challenge, confusing ethics with morals (Rosenstand, 2013, p. 14). "The word morality has a slightly different connotation from that of the terms ethics and values. That is because morality usually refers to the moral rules we follow, the values that we have. Ethics is generally defined as theories about those rules; ethics questions and justifies the rules we live by ...." (Rosenstand, 2013, p. 6).

Ethics in academia is a commonly tossed about phrase frequently intoned by institutional administrators and faculty. The purpose of the commotion is to instill a sense of purpose and integrity into the learning experience for student and instructor alike. Communication technology, as we are aware, can be either miraculous or mischievous. The miracles of course are local and global instantaneous communication anywhere and at any time. The mischievous can range from invasion of our digital privacy to its duplicitous use in plagiarism and testing conventions both inside and outside of the classroom environment.

Certainly, ethics has been part of our interactions with each other since the dawn of time. Moreover, as instructors today and students ourselves in the past; we have seen the good and bad aspects of ethics and the application of morals in the university environment during our tenure.

Cheating is invariably tied to ethics. And ethics is likewise to morality. In academics and in life, our ethics and morality guide our lives. With the proliferation of perpetual connectivity, through both static and mobile devices, the opportunity to remain attached to the information grid and to those with whom we chose to associate is significantly increased. The new world order of the digital landscape has caused a paradigm shift in how both the student and the instructor view the protocols of test taking and the long standing tradition of old world academic integrity and thinking. This study will assess ethical implications of cheating in distance learning classes. The following research questions were explored:

RQ1: Is there a correlation between student's views of ethical conduct in online courses with age, gender, and level of education?

RQ2: Do university students deem it unethical to utilize external sources when taking online courses? 


\section{LITERATURE REVIEW}

When considering ethics and distance education courses, the "age-old concerns about ethical practices in assessment - take on new twists in the distance-learning environment" (Olt, 2002, Abbott, et.al., 2000). The distance which separates students in online classes does not discourage academic dishonesty. In traditional brick and mortar classes, students pass notes or write answers in the palm of their hands if they want to cheat on an exam. Students in online classes do not have to be so clever since in most instances, they are not being monitored during an exam. Using the Internet to search for answers, having another person take the exam or sharing the answers with other classmates are forms of cheating for the online learner. It is becoming very hard for instructors of online classes to catch academic dishonesty.

The need for ethics in distance education is critical to student's success. When students interact face-to-face in traditional classes, they can understand inappropriate or unethical behavior (Gearhart, 2001). When technology comes into play as with distance learning classes, conducting ethical behavior feels less personal because they are unable to see the instructor on the other side of the screen. To address ethics in online courses, Gearhart (2001) suggests setting policies that provide a framework for students to follow and incorporate ethics into the curriculum.

Post and Hapke (2017) describe that online learning integrity falls into two categories: prevention and enforcement. Prevention includes proactive approaches to eliminate the violation from occurring in the first place.

This can be accomplished with the use of an honor code to ensure students adhere to the values set by the university on character and integrity and provides a clear understanding of the consequences of non-compliance. Additionally, Post and Hapke (2017) discuss seven strategies to be incorporated in online courses to develop students' selfregulation and refrain them from violating the academic integrity policies. These strategies include (1) promote task planning and time management, (2) monitor the work as opposed to exams, (3) randomize exam questions for each student, (4) discuss the academic integrity policy, (5) allow asynchronous learning, (6) track student submissions to identify inconsistencies, and (7) provide prompt feedback (Post and Hapke, 2017).

A 2008 study conducted by Toprak, Ozkanal, Kaya and Aydin, analyzed ethics in e-learning. The authors believe that instructors and the institution need to determine their own ethical responsibilities. The expectations must be made at the beginning of the course. Institutions should also have e-Learning policies, guides on legal issues and preventative measures for privacy, plagiarism and copyrights in place (Khan, 2005, Toprak, et.al. 2006). Often time's problems arise when students are not aware of their ethical responsibilities. Students must accept responsibility for the courses they take and participate authentically and refrain from cheating (Toprak, et.al.2006).

Clearly, one of the foremost objectives of an academic institution is to not only instruct but to also imbue in students the value of integrity and ethics both within the classroom setting and in the challenges, that life presents to us each day. Without any values or ethics, organizational and social structures are doomed for failure. Our personal ethics and attitudes are what offers hope for ourselves, the organization, and within the communities that we live and raise our families. This is especially important as we can often be considered a global classroom community due in part to the virtual/online classroom offered by many major and minor universities throughout the world. Of course, we must always respect others and observe the rules, values, and code of conduct of the organization. After all, one never knows who is watching and recording our behavior with the ubiquity of social media and the ever present "smart phone" in the hands of the unsuspecting masses (Chambers, et.al, 2016).

Academic dishonesty is an area of concern for both brick-and-mortar and online academic instructions. In traditional classrooms, faculty can usually monitor student's activities where they can put a face to an actual student. As of February 2016, there are approximately, 5.8 million students who took at least one online course. More than a quarter of higher education students, $28 \%$ are enrolled in at least one online course (Online Consortium, 2017). Courses offered online pose a challenge to educators as students work independently and with very little monitoring by the instructor. Online courses appear to remove barriers of instructor observation and can provide students with an increased opportunity to cheat (Frost, et.al, 2007). Per Grijalva (2002) it is often believed that since students and faculty do not interact face-to-face in most online classes that students will engage in a higher number of cheating incidents than students attending traditional classes. 
Students play a primary role when it comes to academic integrity. They must actively be involved and ultimately responsible for upholding the academic integrity standards set by an academic institution. However, this can become a challenge for universities that have a diverse socioeconomic background including where they are from and their religious background. This poses the challenge to universities to develop their policies around their student base to ensure all students understand it. Bristor and Burke (2016) describe one method implored by a St. Louis based Washington university where they developed an academic policy video that was required to be viewed by all freshman prior to them arriving on campus. While this will help students understand what is required of them, George Washington University implemented a Student Hearing Board to assess situations allegations have been leveled. This helps students develop and enforce the integrity policies set by the university (Bristor and Burke, 2016).

Secondly, the university faculty plays an important role as they are the first-contact for the students. While the instructors should communicate and reinforce the university policy, the university must allow them some flexibility in providing additional guidelines that can help enrich the classroom experience (Bristor and Burke, 2016). The second task for the instructors is to act based upon these policies. Various tools exist to aid this task such as live exams using proctors, avoid using the same exams as prior semesters, change the exam questions from the test bank, utilizing exam pools, and using open-ended questions that relate to the student. Most importantly, instructors must be prepared to act when they determine a violation has occurred (Bristor and Burke, 2016).

A study published by Jones (2011) listed numerous scenarios on what students consider to be cheating or plagiarizing. The following list provide a few examples: submitting another's work as your own, purchasing a research paper or downloading the document from the Internet, cutting and pasting online material without citations, "lifting more than 10 consecutive words from a document without proper acknowledgement," direct copying of an original source document without citation, and submitting assignments used in previous classes

(Jones, 2014, p. 145).

Kelly \& Bonner (2005) examined a population of faculty and administrator perceptions concerning academic dishonesty in distance education environments. "Respondents ranked their top three choices for the reasons students cheat as: 1) grade pressure, 2) uncertainty about what constitutes academic dishonesty, and 3) laziness" (p. 47). Educators past and present should be able to identify with the aspects of grade pressure and laziness as unambiguous culprits. However, the uncertainty aspect of what constitutes academic dishonesty is perplexing. One would hope that by the time a student reaches a post-secondary educational experience they would have learned institutional guidelines of academic integrity and ethics.

According to Bunn, Caudill and Gropper, (2008), it is believed that students cheating behavior can be broken down into two categories. The first is planned cheating which can involve using notes, copying homework, and plagiarizing. Students should be aware that what they are doing is wrong. The second is panic cheating, which can happen when a student is in the middle of taking an exam. While taking the exam, they realize that they are not prepared and look over at another students work for answers. In online courses, planned cheating might be more common than panic cheating due to the nature of the online environment (Grijalva, et.al. 2002) When taking an exam online, students can search for answers online or through the course textbook, by asking a friend for help or they might have another person take the exam.

\section{METHODOLOGY}

With the advent of newer technologies to support distance education in the academic environment, universities need to evaluate academic integrity by understanding students' ethical views of conduct while taking online courses. However, the convenience that distance education provides educators, administrators, and students sometimes overshadows the need to evaluate ethical student conduct within online courses, which could potentially introduce the risk of having students use external sources to complete classwork. External sources are defined as any person, information, material, or equipment that is not included within the course or course content. The study explores the following two research questions:

RQ1: Is there a correlation between student's views of ethical conduct in online courses with age, gender, and level of education? 
RQ2: Do university students deem it unethical to utilize external sources when taking online courses?

The study examined students at two small mid-Atlantic Universities during the month of April 2016. The research utilized a quantitative methodology to assess students' ethical views and how they correlate to demographic attribute. The population chosen for this study was comprised of undergraduate and graduate students enrolled in on-campus and online programs of study. Undergraduate students and graduate students were surveyed in order to gather data from students 18 years of age and older. A total of 457 respondents completed the survey. The survey was designed to obtain information on the respondents' experience with online distance education classes, how they completed their coursework, and if they ever allowed others to complete work on their behalf. Additionally, the survey addressed methods, if any, used to validate student identities in their online courses. The survey was conducted using Survey Monkey, an online tool, to gather and organize data. The data was imported into SPSS for further analysis. This study used Chi-square with a statistical significance at the .05 margin of error with a $95 \%$ confidence level. The study was a convenience sample surveying students from all departments within the university which included the School of Arts and Humanities, Business, Science and Math, Engineering, Computer Science, Information Technology, Criminal Justice and Psychology.

The survey instrument consisted of 18 closed-ended questions and two open ended questions for further understanding of participant comments and responses. Prior to distributing the survey, the researchers conducted a pilot study of the survey to a small group of students to validate the questions' content. Once the pilot was complete, changes were made to the questions and then the survey was distributed using the online tool SurveyMonkey. The first three questions focused on student demographics; which included gender, age, and education level. Questions 4 through 18 asked students if they completed an online course, methods used for student validation, tools / external sources used to complete assignments and exams, their ethical opinion of utilizing external sources measured through 5 choices (Strongly Agree, Somewhat Agree, Neutral, Somewhat Disagree, Strongly Disagree), and their self-assessment of their own personal philosophy when completing online course work. The final two questions asked the students of methods they felt could be implemented to validate student identities and any additional comments they may have about the topic.

\section{RESULTS}

The survey responses were analyzed at both universities and recorded as either University A or University B. University A had students ranging from 18 years of age to 63 years and University B had students ranging from 18 to 47 years of age. Similarly, the study determined that University A had approximately $33.5 \%$ Male students and $66.5 \%$ female students. University B had a similar distribution with $41.4 \%$ Males and $58.6 \%$ females.

The next set of questions determined if students had taken online classes and if so, were authentication methods such as Skype or Biometrics used to validate a student's identity. It is important to note that if students responded "No" to taking an online class, the survey immediately concluded. Both universities had a strong response rate of students who took at least one online class. University A had a $94.2 \%$ response rate of students who took at least one online class while University B had an $87.5 \%$ response rate of students who took at least one online class.

To better understand students' ethical perspectives, each participant was asked if they felt it was ethical to use external resources when taking an online class. Approximately $20 \%$ at each university felt that using external resources when taking an online course was unethical. It is important to note that the survey indicated a list of external resources including mobile devices, other individuals, internet searches, and copies of the exams. A majority of students, felt that using external resources was ethically acceptable when taking an online class. A breakdown of these results for both University A and University B can be seen in Table 1. 
Table 1. Using External Resources for Online Class is Unethical

\begin{tabular}{l|cc}
\hline & University $\boldsymbol{A}$ & University $\boldsymbol{B}$ \\
\hline Strongly Agree & $7.55 \%$ & $12.96 \%$ \\
Somewhat Agree & $11.64 \%$ & $9.26 \%$ \\
Neutral & $17.92 \%$ & $31.48 \%$ \\
$\begin{array}{l}\text { Somewhat } \\
\text { Disagree }\end{array}$ & $23.27 \%$ & $14.82 \%$ \\
Strongly Disagree & $39.62 \%$ & $31.48 \%$ \\
Total & $100.00 \%$ & $100.00 \%$ \\
\hline
\end{tabular}

Additionally, students were asked about their ethical view of using external resources when taking online exams. Opposing their view of using external resources when taking online courses, approximately $61 \%$ of the students at each university felt using external resources when taking an online exam was unethical. Both universities had less than $25 \%$ of the respondents who felt that using external resources while taking an online exam was ethical. Further details of the respondents for each university can be seen in Table 2.

Table 2. Using External Resources for Online Exams is Unethical

\begin{tabular}{l|ll}
\hline & University $\boldsymbol{A}$ & University $\boldsymbol{B}$ \\
\hline $\begin{array}{l}\text { Strongly } \\
\text { Agree }\end{array}$ & $26.65 \%$ & $27.77 \%$ \\
$\begin{array}{l}\text { Somewhat } \\
\text { Agree }\end{array}$ & $27.90 \%$ & $25.93 \%$ \\
Neutral & $26.96 \%$ & $22.22 \%$ \\
$\begin{array}{l}\text { Somewhat } \\
\text { Disagree } \\
\begin{array}{l}\text { Strongly } \\
\text { Disagree } \\
\text { Total }\end{array}\end{array}$ & $12.23 \%$ & $16.67 \%$ \\
\hline
\end{tabular}

Students were asked to gauge their level of ethics when comparing themselves to other students. At both universities, greater than $60 \%$ of the students felt they were either very ethical or average ethical in comparison to other students. University A reported a very small percentage of students who stated they were unethical in comparison to other students. Lastly, University A and University B students reported $29.69 \%$ and $34.0 \%$, respectively, that they felt somewhat ethical in comparison to other students. A detailed breakdown of these results is available in Table 3 . 
Table 3. Self-Evaluation Ethical Comparison.

\begin{tabular}{l|cc}
\hline & University $\boldsymbol{A}$ & University $\boldsymbol{B}$ \\
\hline Very ethical & $43.74 \%$ & $34.0 \%$ \\
Average ethical & $25.63 \%$ & $32.0 \%$ \\
Somewhat ethical & $29.69 \%$ & $34.0 \%$ \\
& & \\
Unethical & $0.94 \%$ & $0 \%$ \\
Total & $100.00 \%$ & $100.00 \%$ \\
\hline
\end{tabular}

One of the objectives of the study was to understand if any statistical correlation existed between demographic characteristics and level of education with the students' responses to the self-evaluation question detailed in Table 3. It was determined that both Age and Level of Education were statistically significant with chi-square values of 0.00 and 0.01 , respectively. The results were determined to be statistically significant if their chi-square value was less than .05 , assuming a $95 \%$ margin of error. A similar analysis was done for University B, however, only the students' responses illustrated that only Level of Education was statistically significant in comparison to their selfevaluation responses. Additional metrics for these two universities can be found in Tables 4 through 11 .

Table 4. Statistical Correlation University A

\begin{tabular}{l|ccc}
\hline & Chi Square Value & $\boldsymbol{d f}$ & Value \\
\hline Age & 0.00 & 36.00 & 72.88 \\
Gender & 0.56 & 8.00 & 6.80 \\
Level of Education & 0.01 & 20.00 & 38.78 \\
\hline
\end{tabular}

Table 5. Statistical Correlation University B

\begin{tabular}{l|ccc}
\hline & Chi Square Value & $\boldsymbol{d f}$ & Value \\
\hline Age & 0.13 & 15.00 & 21.13 \\
Gender & 0.45 & 6.00 & 5.74 \\
Level of Education & 0.00 & 9.00 & 29.11 \\
\hline
\end{tabular}

Table 6. Age versus Self-Evaluation University A

\begin{tabular}{l|cccc}
\hline Age & Un-ethical & $\begin{array}{c}\text { Somewhat } \\
\text { ethical }\end{array}$ & $\begin{array}{c}\text { Average } \\
\text { ethical }\end{array}$ & $\begin{array}{c}\text { Very } \\
\text { ethical }\end{array}$ \\
\hline $\mathbf{1 8 - 2 2}$ & $0.51 \%$ & $18.58 \%$ & $9.92 \%$ & $6.36 \%$ \\
$\mathbf{2 3 - 2 7}$ & $0.00 \%$ & $12.72 \%$ & $7.12 \%$ & $10.18 \%$ \\
$\mathbf{2 8 - 3 2}$ & $0.25 \%$ & $3.56 \%$ & $1.53 \%$ & $4.83 \%$ \\
$\mathbf{3 3 - 3 7}$ & $0.00 \%$ & $1.53 \%$ & $1.02 \%$ & $3.05 \%$ \\
$\mathbf{3 8 - 4 2}$ & $0.00 \%$ & $1.78 \%$ & $0.25 \%$ & $3.31 \%$ \\
$\mathbf{4 3 - 4 7}$ & $0.00 \%$ & $2.04 \%$ & $0.00 \%$ & $3.82 \%$ \\
$\mathbf{4 8 - 5 2}$ & $0.00 \%$ & $1.02 \%$ & $0.51 \%$ & $1.27 \%$ \\
$\mathbf{5 3 - 5 7}$ & $0.00 \%$ & $0.51 \%$ & $0.00 \%$ & $2.04 \%$ \\
$\mathbf{5 8 - 6 2}$ & $0.00 \%$ & $0.51 \%$ & $0.25 \%$ & $0.76 \%$ \\
$\mathbf{6 3 +}$ & $0.00 \%$ & $0.51 \%$ & $0.25 \%$ & $0.00 \%$ \\
Total & $0.76 \%$ & $42.75 \%$ & $20.87 \%$ & $35.62 \%$ \\
\hline
\end{tabular}


Table 7. Gender versus Self-Evaluation University A

\begin{tabular}{l|llll}
\hline Gender & Un-ethical & Somewhat ethical & Average ethical & Very ethical \\
\hline Female & $0.26 \%$ & $26.60 \%$ & $14.32 \%$ & $25.32 \%$ \\
Male & $0.51 \%$ & $16.11 \%$ & $6.65 \%$ & $10.23 \%$ \\
Total & $0.26 \%$ & $26.60 \%$ & $14.32 \%$ & $25.32 \%$ \\
\hline
\end{tabular}

Table 8. Level of Education versus Self-Evaluation University A

\begin{tabular}{l|llll}
\hline Level of Education & Un-ethical & Somewhat ethical & Average ethical & Very ethical \\
\hline Graduate Masters & $0.26 \%$ & $16.11 \%$ & $8.70 \%$ & $19.69 \%$ \\
Undergraduate Senior & $0.26 \%$ & $14.07 \%$ & $6.14 \%$ & $9.46 \%$ \\
Undergraduate Junior & $0.00 \%$ & $5.12 \%$ & $3.58 \%$ & $3.84 \%$ \\
Undergraduate Sophomore & $0.26 \%$ & $3.84 \%$ & $1.53 \%$ & $2.05 \%$ \\
Undergraduate Freshman & $0.00 \%$ & $3.84 \%$ & $1.02 \%$ & $0.26 \%$ \\
\hline
\end{tabular}

Table 9. Age versus Self-Evaluation University B

\begin{tabular}{l|cccc}
\hline Age & Un-ethical & Somewhat ethical & Average ethical & Very ethical \\
\hline $\mathbf{1 8 - 2 2}$ & $0.00 \%$ & $31.25 \%$ & $20.31 \%$ & $9.38 \%$ \\
$\mathbf{2 3 - 2 7}$ & $0.00 \%$ & $1.56 \%$ & $4.69 \%$ & $1.56 \%$ \\
$\mathbf{2 8 - 3 2}$ & $0.00 \%$ & $6.25 \%$ & $0.00 \%$ & $4.69 \%$ \\
$\mathbf{3 3 - 3 7}$ & $0.00 \%$ & $1.56 \%$ & $1.56 \%$ & $7.81 \%$ \\
$\mathbf{3 8 - 4 2}$ & $0.00 \%$ & $3.13 \%$ & $0.00 \%$ & $3.13 \%$ \\
$\mathbf{4 3 - 4 7}$ & $0.00 \%$ & $1.56 \%$ & $0.00 \%$ & $1.56 \%$ \\
Total & $0.00 \%$ & $45.31 \%$ & $26.56 \%$ & $28.13 \%$ \\
\hline
\end{tabular}

Table 10. Gender versus Self-Evaluation University B

\begin{tabular}{l|llll}
\hline Gender & Un-ethical & Somewhat ethical & Average ethical & Very ethical \\
\hline Female & $0.00 \%$ & $17.46 \%$ & $12.70 \%$ & $12.70 \%$ \\
Male & $0.00 \%$ & $26.98 \%$ & $14.29 \%$ & $15.87 \%$ \\
Total & $0.00 \%$ & $44.44 \%$ & $26.98 \%$ & $28.57 \%$ \\
\hline
\end{tabular}

Table 11. Level of Education versus Self-Evaluation University B

\begin{tabular}{l|llll}
\hline Level of Education & Un-ethical & Some-what ethical & Average ethical & Very ethical \\
\hline Graduate Masters & $0.00 \%$ & $3.13 \%$ & $0.00 \%$ & $0.00 \%$ \\
Undergraduate Senior & $0.00 \%$ & $12.50 \%$ & $10.94 \%$ & $6.25 \%$ \\
Undergraduate Junior & $0.00 \%$ & $17.19 \%$ & $4.69 \%$ & $10.94 \%$ \\
Undergraduate Sophomore & $0.00 \%$ & $45.31 \%$ & $26.56 \%$ & $28.13 \%$ \\
Undergraduate Freshman & $0.00 \%$ & $12.50 \%$ & $10.94 \%$ & $10.94 \%$ \\
\hline
\end{tabular}




\section{DISCUSSION}

The first research question looked at both universities to see if a correlation existed between the respondents' selfevaluation question and the three variables (age, gender, and level of education). The greatest response rate was centered around "Somewhat ethical in comparison to other students", while it was important to see that a very limited number of students at University A and no students at University B felt that they were "Unethical" in comparison. Given the low response rate for "Unethical", one could assume that students did not want to be categorized in such a taboo grouping and may have decided to choose the next ranking of "Somewhat" which led to the larger response rate. Additionally, males seemed to evaluate themselves as less ethical in comparison to the females.

University A found both age (0.00) and Level of Education (0.01) to be statistically significant with the selfevaluation, while University B found that only Level of Education $(0.00)$ was statistically significant. Based upon the results, it seems as the age increased, students felt they were more ethical in comparison to other students. Additionally, level of education yielded similar results with higher levels of education illustrating those students felt they had a higher level of ethics. When looking at these two results, age can be correlated with level of education being that as we move into the next year of our academic career, we are getting older and have gained additional life / academic experiences that may mold our ethical principles. In a nutshell, as we get older, students find themselves being more ethical. Therefore, faculty and administrators may consider using less ethical and academic integrity measures for advanced courses or courses with students higher in age.

The second research question focused on the students' perspectives of using external resources such as mobile devices and internet searches in their courses and online courses and exams. The results illustrated that the majority of students recognized that exams are meant to test what they have learned and using external resources would unethical when taking an online exam. However, students felt using external resources when completing coursework outside of exams was acceptable and ethical.

It can be assumed that students are leveraging external resources to help enhance their knowledge on the covered topics. Given these two statistics, it would be recommended that faculty and administrators continue to improve online exams to help combat external resources being used or implement exams that would allow external resources but go past the simple definitional / theory questions to test the students' abilities of applying the learned concepts. Lastly, it would also be recommended that courses incorporate external resources in their overall course rather than finding methods to exclude them. Many learn best by researching the topic outside of the course shell. Given that students find the use acceptable, we should embrace it and allow them to broaden their knowledge rather than restricting them to content solely in the course shell.

\section{CONCLUSION}

Academic integrity has long plagued the educator. From grade school neophytes to doctoral degree candidates the temptation to and the admission of cheating endures. Cheating is perhaps not the most politically correct or sensitive description of academic dishonesty. But that is exactly what it is. Cheating is cheating. It does not matter if one is plagiarizing another's work, using crib sheets, or using an ancillary electronic device to circumvent security protocols when completing exams or other assignments.

Mobile device ubiquity and its simplicity of use have brought the world to the students' fingertips. Information, be it right or wrong, is only a click or two away. It is no small wonder that students are tempted to claim another's work or ideas as their own.

These facts can lead faculty and administrators down one of two paths. Either find better ways to restrict the use of external resources or embrace its use and find creative ways to enhance the course. Like the old saying "if you can't beat them, join them," this is a prime opportunity for universities to enrich their online courses past simple postings of PowerPoints and exams and implement interactive course material that drives and motivates students to go beyond the course content and truly gain an in-depth knowledge of the course materials.

James (2002) Four-part strategy of ensuring fairness include 1) a collaborative effort on the part of universities and staff to create policies and strategies to combat academic dishonesty, 2) educate students about the academic expectations by having students acknowledge intellectual merit, 3) design approaches that will help minimize 
academic dishonesty, and 4) install visible procedures and monitoring for catching academic dishonesty followed by and appropriate action.

\section{REFERENCES}

Abott, L., Siskovic, H., Nogues, V., \& Williams, J.G. (2000). Student assessment in multimedia instruction: Considerations for the instructional designer. Retrieved on April 25, 2017 from http://newfirstsearch.oclc.org

Bristor, J. \& Burke, M. (2016). Academic Integrity Policies: Has your institution implemented and effective policy? Retrieved on May 7, 2017 from http://www.aejournal.com/ojs/index.php/aej/article/view/338/169

Bunn, D.N., Caudill, S.B., \& Gropper, D.M. (1992). Crime in the classroom: An economic analysis of undergraduate student cheating behavior. Journal of Economic Education, 23 (Summer): 197-207

Chambers, C., \& Ransom, H. (2016). Teaching ethics in higher education using the values - issues - action (VIA) model. Retrieved on May 10, 2017 from http://www.jspte.org/Volume1/JSPTEv1p013034Chambers2120.pdf

Frost, J., Hamlin, A., \& Barcyzy, C. (2007). A survey of professor reactions to scenarios of academic dishonesty in American universities. Journal of Business Inquiry: Research, Education, and Application, 6(1), 11-18.

Grijalva, T., Kerkvliet, J. \& Nowell, C. (2002). Academic dishonesty and online courses. Retrieved on April 10, 2017 from http://oregonstate.edu/dept/econ/pdf/cheat.online.pap6.pdf

James, R. McInnis, C., \& Devlin, M. (2002). Assessing the learning in Australian higher education and Australian universities teaching committee. Assessing learning in Australian universities : ideas, strategies and resources for quality in student assessment. Australian Universities Teaching Committee/Centre for the Study of Higher Education, Melbourne University, [Australia]

Jones, D. L. R. (2011, June). Academic dishonesty: Are more students cheating? Business Communication Quarterly, 74(2), 141-150

Kelly, K.B., \& Bonner, K. (2005). Digital test, distance education and academic dishonest: Faculty and administrator perceptions and responses. Journal of Asynchronous Learning Networks. 9(1). 43-53. Retrieved on May 2, 2017 from http://www.msmc.la.edu/include/learning_resources/online_course_environment/online_teaching/v9n1_dis honesty.pdf

Online Learning Consortium (2016, February). Report: One in four students enrolled in online courses. Retrieved on May 5, 2017 from https://onlinelearningconsortium.org/news_item/report-one-four-students-enrolledonline-courses/

Post, A. \& Hapke, H. (2017). Online learning approaches: Current practices and future solutions. Retrieved on May 1, 2017 from https://olj.onlinelearningconsortium.org/index.php/olj/article/view/843/256

Roprak, E., Ozkanal, B., Kaya, S., \& Aydin, S. (2006). What do learners and instructors of online learning environments think about ethics in e-learning: A case study from Anadolu University. Retrieved on April 1, 2017 from http://asianvu.com/digital-library/elearning/ethics.pdf

Rosenstand, N. (2013). The moral of the story: An introduction to ethics. ( $7^{\text {th }}$ ed.), New York, NY: McGraw-Hill. 